\title{
Sublimação: \\ a retórica das forças da natureza
}

\begin{abstract}
Abertura
Será a forma do recipiente que é semelhante? A actividade intelectual é muitas vezes comparada com a purificação que tem lugar quando se dá uma mudança de estado.

Molière afirma: «sou a favor do bom senso e não poderia suportar as ebuliçð̃es cerebrais dos nossos marqueses de Mascarille» '. Madame de Sévigné faz o seguinte retrato do Cardeal de Retz: «Salvo o quarto de hora em que dá pão às trutas, passa o resto do tempo em destilaçð̄es e distinçðes de metafísica... que o matam " ${ }^{2}$. Balzac, muito para além da figura de estilo, está convencido de que «o nosso cérebro é o matrás onde transportamos o que as nossas diversas organizaçð̋es podem absorver de matéria etérea, base comum de várias substâncias conhecidas sob os nomes impróprios de electricidade, calor, luz, fluido galvânico, magnético, etc., e de onde sai sob a forma de pensamento' ${ }^{3}$.
\end{abstract}

Francis Ponge, grande poeta francês contemporâneo, inscreve-se nesta linhagem ilustre: para justificar a escolha de um rio, o Sena, como tema de um dos seus poemas em prosa - urdido com o deleite verbal e a minúcia de um Burgess ou de um Nabokov - dedica-se, antes de mais, a fazer uma descrição exacta das forças intermoleculares e da posição intermédia dos líquidos, em relação aos sólidos e aos gases.

Vem-lhe então à mente, tal qual o ressalto de um seixo na água, a reflexão de que «existe um estado do pensamento em que este é a um tempo demasiado agitado, demasiado distendido, demasiado isótropo para ser exprimível - corrrespondendo este estado ao de um gás francamente acima da sua temperatura crítica, quando não é liquidificável; um outro estado do pensamento em que este se aproxima da exprimabilidade sendo este estado análogo ao de um gás liquidificável, ou vapor; basta que a pressão aumente e que a temperatura baixe para que a palavra possa aparecer, primeiramente em suspensão, tratando-se então de um estado lógico comparável ao de um gás no estado de vapor em saturação; em seguida surge uma superfície de separação, quando pensamento e escrita coexistem sob a mesma pressão, e é como quando o líquido cai no fundo do vaso. Mas eis que o mais importante: a partir deste momento, e apesar da indubitável não descontinuidade entre o pensamento e a sua expressão verbal, igual à que existe entre o estado gasoso e o estado liquido da matéria - o escrito apresenta caracteres que o tornam muito próximo da coisa significada, ou seja dos objectos do mundo exterior, do mesmo modo que o liquido está muito próximo do sólido. A diferença consiste em ele ter a faculdade de encontrar uma configuração de energia livre minima. De tal modo que a adequação da escrita aos objectos exteriores líquidos é não apenas não utópica mas, por assim dizer, fatal e como que antecipadamente certa de ser realizada, bastando para tal que tudo seja feito para que a escrita seja o que a escrita deve ser por definição... quer dizer, provida de todas as qualidades análogas às dos líquidos» ${ }^{4}$.

\section{Um duplo emprego}

Os dicionários confirmam este emprego antiquíssimo de termos técnicos, provenientes da química, para designar operaçðes intelectuais ou valores morais. No século XVII, o vocábulo «distillation» usado por Madame de Sévigné, encontra-se no Dictionnaire de Furetière: «Distiller usa-se em moral com um sentido figurado. Distiller o espirito em qualquer coisa, quando este corre o perigo de se evaporar devido a uma aplicação demasiado forte" 's. Satisfeito, Ponge?

De igual modo, a sublimação, «operação de química, por meio da qual as partes voláteis de um corpo, elevadas pelo calor do fogo, se fixam à parede superior de um vaso" " , está associada a sublime que é «uma característica extraordinária, maravilhosa, que enleva, seduz e arrebata» 7.8 .

As etimologias não deixam de ter interesse, o termo distillatio, em latim, significa uma constipação, um catarro. Nostradamus ainda o usa nesse sentido:

«La bouche et gorge en fervides pustules, De sept Grands cinq. Toux distillante muire; Pluye si longue, à non mort tournent bulles, Le Grand mourir, qui trestous faisait luire" " 9.

Quanto aos vocábulos sublimar, sublimação, Bloch e von Wartburg datam o primeiro do século XVI, «como termo de alquimia, posteriormente conservado na linguagem da química" ${ }^{10,11}$, ao passo que o segundo, derivado do latim dos alquimistas, aparece no século XV. "Os sentidos figurados foram por vezes detectados no verbo, em 1350, e ainda em Amyot, no substantivo, no século XVI.»

\section{O sublimado corrosivo}

O sublimado corrosivo surge na literatura no século $\mathrm{XV}$, em Villon ${ }^{11}$.

Abro aqui um parêntesis: o mercúrio e os seus derivados tinham uma importância fundamental para os alquimistas. A literatura das ciências ocultas, a lite-

\footnotetext{
* Traduzido do Nouveau Journal de Chimie, vol. 3, n. ${ }^{\circ} 6$ (1979) por Ana Bastos com a autorização do autor e do editor. O poema de Raymond Queneau foi traduzido por Luisa Costa Gomes.
}

a Universidade de Liège. 
ratura pura e simples, então pejadas de alusð̃es, de imagens e de alegorias, habilmente entretecidas numa grinalda posta em verso por Raymond Queneau em homenagem simultânea ao metal que simbolizamos por $\mathrm{Hg}$ e ao deus Mercúrio/Hermes:

\section{Evitando dos esplendores a fatal amálgama}

e já quase a surgir em colunas fluentes para tentar no céu o calor polígamo ou curvar o vário em arco oscilatório do belo seco sexo flexo ferro fixo das tempestades fluentes maravilha do liquido êxtase elemental e fluido e subtil em gotas desenhada gotas brincadoras e risonhas mais que ludiðes único que foi deus o barroco metal escorrida p'lo corpo da bola sólida perfeitamente puro não formava linha mais tarde visará o irmão planetário mais tarde visará o tormento sifilitico mais tarde visará a explosão fulminante ele visará mais alto que o manual escolar que lhe dá um cortejo d'oitenta electrões visará mais alto que a urna boticária e que o sublime mesmo se é corrosivo ou que a lembrança de um negro laxativo nado nativo do cinábio emisso pela ilusão serpente verde uivando ao pé d'árvore de Diana pai autoliceal guia das defunçסes percorredor d'infernos liberador d'almas direç̧ão do poeta algoritmo alquímico $t u$, do retrato marco que insultou Alcibiades fascista prosaico e admirador dos Persas tu que sabes polir com tua língua transversa os trabalhos inspirados aos que forjam os ritmos minador da alusão tralhador de metáforas Hermes explica aos seus franceses leitores a clareza do carme em seis partes diviso Mercúrio lhes ajusta a castúcia artesiana à ingénua sinopse do pequeno poema.

Não é... sublime? Tanto mais que «o sublime é o sentimento de uma liberdade superior» ${ }^{13}$.

\section{E Freud?}

Vimos que a analogia do pensamento com as mudanças de estado que são a destilação e a sublimação é antiga, remontando seguramente aos alquimistas. Todavia, o termo sublimação, na sua utilização corrente não química, tem actualmente o significado que the foi atribuido por Freud no princípio do século. Sabe-se que Freud, principalmente no seu texto sobre «Uma recordação de infância de Leonardo da Vinci", designa assim a transformação da líbido numa obra original que se verifica nos grandes criadores, artistas, músicos e escritores. Segundo Freud «designa-se por sublimação esta capacidade de trocar o objectivo sexual originário por um outro, já não sexual, mas que lhe é fisicamente aparentadon' ${ }^{14}$. Esta denominação freudiana é pouco precisa: não se sabe muito bem se Freud teria acima de tudo em mente a noção figurada, abstracta, do sublime, resultante de um rasgo fulgurante que nos eleva às alturas, com esse travo maravilhoso de liberdade evocado por Alain ${ }^{13}$. Ou tratar-se-á sobretudo de uma operação concreta por meio da qual os químicos purificam uma substância, efectuando a transformação de um sólido em gás, seguida da transformação inversa que deposita o sólido puro numa parede fria? Em am- bos os casos, é curioso que Freud pareça pôr a sexualidade a um nivel inferior do da obra de arte. Puritanismo da sua parte? Com efeito, a sublimação freudiana que se realiza, num tempo intermédio, através de uma ocultação da líbido pelo eu, desde que este tenha uma dimensão narcísica suficiente, tem simultaneamente a ver com o sublime artístico e com a sublimação do químico ${ }^{15}$, não passando de um conceito mal definido, vago. É lamentável que a psicanálise se tenha assim apossado de uma palavra que, não obstante a sua longa história, sucintamente evocada no presente texto, era ainda cheia de vigor para o restituir com um sentido enfraquecido.

Temos aqui um exemplo nítido dos múltiplos elementos que a psicanálise foi buscar à alquimia. Não é surpreendente que quimica e psicanálise tenham conceitos e vocábulos comuns, uma vez que ambas derivam, embora em épocas diferentes, do mesmo passado alquímico ${ }^{16,17}$.

\section{Fecho}

A sabedoria, o saber, passam por uma sublimação prévia. O sublime, na gíria do século XIX, é aquele que sabe (entenda-se: que é iniciado na giria) ${ }^{18}$.

Os alquimistas, esses iniciados, representavam a sublimação por aves, águias ou pombas, a levantar voo. Do ponto de vista da sucessão as cores, tão importante para a Obra hermética, o tempo da sublimação é aquele em que a escuridão dá lugar às cores da túnica de Iris, mensageira dos Deuses.

Tal como, ao alvorecer, à medida que o sol se vai erguendo, a noite dá lugar ao «cinzento, ao verde, ao branco, que se tinge de amarelo (citrino), passa ao amarelo alaranjado, ao ocre, cor de Marte e, finalmente, ao vermelho, sendo esta última a cor da pedra filosofal, a que tem o poder de transmutar os metais e que, bem entendido, corresponde a uma sublimação interna psicológica do alquimista" ${ }^{19}$.

\section{Referências}

1 - Critique de l'École des Femmes, 6.

2 - Manuscrito de Grosbois V, 365, 366; citado por J.E.A. Sommer, Lexique de la langue de Madame de Sévigné, Hachette, Paris, 1866

3 - Balzac, Louis Lambert, nova edição da Pléiade (P.G. Castex), Gallimard, Paris XI. A frase "O homem è um matrás" surge tambèm em La Recherche de l'Absolu. Bruxelas, Société Belge de Librairie, Hauman, Cattoir et Cie., 1837, pg. 129.

4 - F. Ponge, La Seine, em Tome Premier, Gallimard, Paris, 1965. Agradeço a Lionel Salem por me ter assinalado este texto maraviIhoso.

5 - Dictionnaire de Furetière.

6 - L. Aubanel, Nouveau Vocabulaire de l'Académie Française, Avignon, 1822

7 - Encyclopédie de Diderot e d'Alembert, Paris, 1751-1780, artigo de Chevalier de Jaucourt.

$\mathrm{Na}$ mesma nalavra "sublime" existe também um artigo de Marmontel que diz nomeadamente: "o sublime é na generalidade uma percepçăo rápida, luminosa e profunda, um resultado bruscamente carregado de sentimentos ou pensamentos, cuja natureza está mais ligada àquilo que faz ouvir do que àquilo que exprime... O que do ponto de vista da expressåo é mais essencial no sublime é a energia e sobretudo a precisăo; o que mais the repugna é a abundância e a ostentaçào das palavras".

8 - Condillac è de certo modo banal: «sublime é algo relativo ao espirito, ao mérito, ao estilo, aos pensamentos e caracteriza o mais elevado grau de elevaçãon, Dictionnaire des Synonymes, obras filosóficas, G. Le Roy editor, Presses Universitaires de France, Paris, 1951. 
9 - Présages, XII; em Les Oracles, de Michel de Nostredame, 2. Slatkine Reprints, Genève, 1969.

10 - «Significando submeter ao calor corpos sólidos num recipiente fechado de forma que os elementos voláteis ascendam até à parte superior do recipiente ai se tornando novamente sólidos e ai se fixando."

11 - O. Bloch e W. von Wartburg, Dictionnaire Étymologique de la Langue Française, Presses Universitaires de France, 6. ${ }^{a}$ edição, 1975. 12 - R. Queneau, Petite Cosmogonie Portative, Gallimard, Paris, 1950 (Canto Terceiro).

13 - Alain, Propos, Édition de la Pléiade, Gallimard, Paris, 1970 2, 1072, formulação n. ${ }^{\circ} 625$ (Julho de 1935).

14 - S. Freud, Gesammte Werke, VII, 150; Standard Edition, IX, 187.

15 - «A palavra sublimação introduzida por Freud em psicanálise evoca simultaneamente a noção de sublime utilizada nomeadamente no campo das belas-artes para designar uma produção que sugere grandeza, elevação, e a noção de sublimação utilizada em quimica para designar a transformação através da qual um corpo passa directamente do estado sólido ao estado gasoson, J. Laplanche e J.B. Pontalis, Vocabulaire de la Psychanalyse, Presses Universitaires de France, Paris, 1967 (artigo "sublimação»).

16 - P. Laszlo, Intelligence totale, idéologies totalitaires, ERIS, Buletin du GERSULP, 4, 1-17 (1977).

17 - P. Laszlo, Toutes sortes d'affinités, Nouv. J. Chim., 2, 435$-436(1978)$.

18 - Ao escrever L'Assomoir Zola inspirou-se, para as frases de "argot» que figuram nesse livro, na obra de Denis Poulot Le sublime ou le Travailleur tel qu'il est, A. Lacroix, Verbockhoeven et Cie, Paris, 1870. Agradeço ao Professor Philippe Lecarme por me ter chamado a atenção para este aspecto.

19 - P. Laszlo numa estrevista realizada por M. Rouzé na emissão "Os caminhos do conhecimento: olhares sobre a ciência", France-Culture, 20 de Novembro de 1976.

\title{
Jarra comemorativa dos 75 anos da S.P.Q.
}

\author{
Jarra Botica, modelo do séc. XVII, pŕoduzida para a S.P.Q. pela Cerâmica \\ de Conímbriga; cor azul em fundo branco
}

Preço unitário:

- compra na sede em Lisboa ou na sede da Delegação Norte (Porto).

$1800 \$ 00$

- preço incluído porte de correio

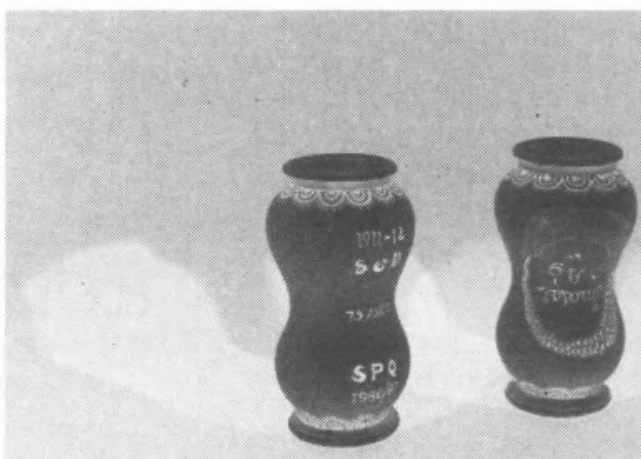

CORTE POR AQU

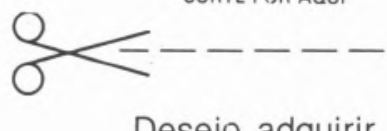

$2100 \$ 00$

Desejo adquirir jarras comemorativas dos 75 anos da S.P.Q., para o que junto o cheque n. ${ }^{\circ}$ do Banco escudos.

Nome:

Morada para entrega: 